\title{
RANDOMIZED DOUBLE BLIND CLINICAL TRIAL OF INTRAMUSCULAR DEXMEDETOMIDINE V/S MIDAZOLAM AS PREMEDICATION IN PAEDIATRIC SURGICAL PATIENTS
}

\author{
Anmol Kambow ${ }^{1}$, Naseema Kanase ${ }^{2}$, Arvind Nadkarni ${ }^{3}$ \\ ${ }_{1} 3^{\text {rd }}$ Year Post Graduate Student, Department of Anaesthesia, Krishna Institute of Medical Sciences, Karad. \\ 2 Professor, Department of Anaesthesia, Krishna Institute of Medical Sciences, Karad. \\ 3 Professor, Department of Anaesthesia, Krishna Institute of Medical Sciences, Karad.
}

\begin{abstract}
\section{OBJECTIVE}

A genuine attempt was made to find ideal drug for premedication in paediatric surgical patients. Dexmedetomidine a newer, highly selective alpha-2 agonist was compared to midazolam via intramuscular route. Setting: Institute-Department of Anaesthesiology, Krishna Institute of Medical Sciences.
\end{abstract}

\section{METHODS}

Dexmedetomidine group (Group D) with the conventional Midazolam group (Group M) was compared for premedication in cases of paediatric surgical patients. A total of sixty patients, scheduled for elective surgery of duration 15 to 90 minutes, were enrolled and randomly assigned in a double blind manner to Group D and Group M. Intramuscular Dexmedetomidine (1.5 mcg/kg) in Group D or midazolam $(0.05 \mathrm{mg} / \mathrm{kg})$ in Group $\mathrm{M}$, as a premedication in preoperative room was given and sedation score with Ramsay sedation scale and parent separation anxiety score were recorded. After 45 mins, patient was shifted in the operation room and a standard technique of anaesthesia was applied to all patients. Mask acceptance score, wake up score, demand of post-op analgesia, time for first analgesia requirement were recorded.

\section{RESULTS}

Our study comparing dexmedetomidine with midazolam premedication found a stable heart rate and blood pressure with comparable sedative effects, ( $90 \%$ vs $56 \%$ ), P value 0.0074 concluded that dexmedetomidine group had better sedative effect. Parent separation anxiety score was better with dexmedetomidine group compared to midazolam group with p value 0.0419 ( $93 \%$ vs $70 \%)$. Mask acceptance was better with dexmedetomidine group compared to midazolam group with p value 0.0153 (90\% vs 60\%). Wake up score were compared and dexmedetomidine was better than midazolam with p value 0.0001 (93\% vs $46 \%$ ).

\section{CONCLUSION}

Premedication with low-dose intramuscular dexmedetomidine resulted in better sedation, lower anxiety levels during parent separation, better mask acceptance and wake up behaviour as compared with low-dose intramuscular midazolam.

\section{KEYWORDS}

Dexmedetomidine; Midazolam; Intramuscular; Premedication; Children.

HOW TO CITE THIS ARTICLE: Kambow A, Kanase N, Nadkarni A. Randomized double blind clinical trial of intramuscular dexmedetomidine v/s midazolam as premedication in paediatric surgical patients. J. Evolution Med. Dent. Sci. 2016;5(42): 2566-2570, DOI: $10.14260 /$ jemds/2016/600

\section{INTRODUCTION}

Patient comfort and convenience is a greater consideration in $21^{\text {st }}$ century. The acquisition of recent technology and skills now affords a better choice for paediatric surgeries. To match this goal, innovations in technique of anaesthesia becomes mandatory. Major problem with paediatric age group is preoperative crying, agitation, anxiety, apprehension with restlessness during separation from parents which results in great difficulty in securing an IV line or application of mask before induction of anaesthesia. Variables such as situational anxiety of the mother, temperament of the child, age of the child and quality of previous medical encounters predict a child's preoperative anxiety. ${ }^{1}$

Financial or Other, Competing Interest: None.

Submission 07-04-2016, Peer Review 30-04-2016,

Acceptance 07-05-2016, Published 24-05-2016.

Corresponding Author:

Dr. Anmol Kambow,

A/8, Kanwal Apartment-4,

Bungalow Road, Andheri West,

Mumbai-53.

E-mail:anmol_kam@yahoo.com

DOI: $10.14260 /$ jemds $/ 2016 / 600$
Preoperative anxiety has been shown to delay the induction of anaesthesia (Kain, Mayes, $\mathrm{O}^{\prime}$ Connor, and Cicchetti, 1996) and provoke the release of stress hormones, which can hinder recovery (McCann and Kain, 2001).

Visintainer and Wolfer (1975), in their classic study classified five dimensions of the surgical experience that can evoke anxiety in children: (a) physical harm or bodily injury in the form of pain, mutilation or even death; (b) separation from parents and absence of trusted adults, especially for preschool children; (c) fear of the unknown and unfamiliar; (d) uncertainty about "Acceptable" and normative behaviour in a hospital setting; and (e) loss of control, autonomy and competence. ${ }^{2}$ Emergence Agitation (EA) from anaesthesia is common in children, especially in the preschool age group who undergo general anaesthesia. It has been described as a mental disturbance during the recovery from general anaesthesia and can consist of hallucinations, delusions and confusion in the child. For preoperative sedation and anxiolysis, midazolam (Benzodiazepine) is used Intramuscular since decades. When administered preoperatively, the drug relieves anxiety and provides sedation and anterograde amnesia of perioperative events. 
Midazolam has been administered orally as a hypnotic for the short term management of insomnia.

Dexmedetomidine is a potent and highly selective alpha-2 adrenoreceptor agonist, recently introduced into clinical practice for sedation and analgesia. Intramuscular Dexmedetomidine is being considered as a premedication in paediatric age group with a promise to produce sedation, anxiolysis and does not produce respiratory depression. It also possibly decreases total opioid consumption in perioperative period. In the last few years, it has emerged as a promising therapeutic drug in wide range of anaesthetic management for benefits in the perioperative periods.

This study analyses and compares the efficacy of midazolam and dexmedetomidine when used intramuscularly as a premedication in paediatric surgeries.

\section{MATERIAL AND METHODS}

The study was conducted after the approval of Ethical Committee of the Institution and with the informed consent given by the patient. It was a randomized, double blind, comparative parallel group study involving 60 patients, distributed equally 30 each in Group 1 (Study drug Midazolam) and Group 2 (Study drug Dexmedetomidine).

\section{Sample Size}

Initially, we did a pilot study of 20 patients; 10 in each Group 1 and 2 as an open drug study. With $\alpha=0.05$ and a power of $80 \%$, detect difference of $30 \%$ in the satisfactory target sedation score, calculated sample size is 30 per group.

\section{Technique}

Study was carried out as a part of our routine anaesthetic services in paediatric patients. Patients were adequately evaluated in preanaesthetic checkup. Only ASA1 and ASA2 status were included for the study with age 3 to 14 years (14 $\mathrm{kg}-45 \mathrm{~kg}$ ). Short surgical procedure from $15 \mathrm{~min}$ to $90 \mathrm{~min}$ were selected. Exclusion Criteria were ASA III or higher, surgery lasting for more than $90 \mathrm{~min}$, congenital diseases, coagulation disorders, known allergic reaction to dexmedetomidine or midazolam, serious pre-existing impairment of respiratory, cardiovascular, hepatic, renal, neurological or endocrine functions, severe upper airway infection, predicted difficult airway, pre-existing psychiatric disorders.

All patients were kept fasting according to guidelines. A functional self-inflating resuscitation bag with reservoir, emergency drugs such as Atropine, a working laryngoscope with appropriate size blades, laryngeal mask airway and endotracheal tube were kept ready.

On arrival in pre-operation room Heart Rate (HR), Systolic Blood Pressure (SBP), Diastolic Blood Pressure (DBP), Mean Arterial Blood Pressure (MAP) and Pulse Oximetry (SpO2) was recorded. Randomization was done by fellow anaesthesiologist who used computer generated randomization to give premedication, either midazolam or dexmedetomidine intramuscularly in a volume of $2 \mathrm{~mL}$. No child received any premedication before arrival in the preoperative room.
On arrival in the pre-operation room after assessing the haemodynamic parameters, intramuscular premedication was given by a fellow anaesthetist as per randomization, who did not participate any further in the conduct of study.

Premedication was administered to each patient intramuscularly with midazolam $0.05 \mathrm{mg} / \mathrm{kg}$ and dexmedetomidine $1.5 \mathrm{mcg} / \mathrm{kg}$. In the pre-operative room before shifting to the operation theatre, sedation levels were assessed using Ramsay Sedation Score every ten minutes.

Anxiety during parental separation was assessed by Parental Separation Anxiety Scale (PSAS); Sedation score was assessed from the administration of drug with 6 point Ramsay sedation score for maximum of 45 mins., where scores of 4-6 are satisfactory. Secondary outcome measures included parent separation anxiety score, which were noted just before shifting the patient in the operation theatre and were recorded as per. Parent separation anxiety score of 4 points where 1, 2 are satisfactory. After 45 mins., child was transferred to the operation theatre.

A standard technique for conduct of anaesthesia was maintained for all the patients. After placement of routine monitoring, each child received an intravenous cannula and was given $1 \mu \mathrm{g} / \mathrm{kg}$ of intravenous fentanyl, anaesthesia was induced by inhaled sevoflurane $2-5 \%$ in oxygen using a modified Jackson-Rees anaesthesia system via transparent face mask kept gently on face. Endotracheal intubation was performed in all cases without the aid of muscle relaxation and anaesthesia, thereafter maintained with sevoflurane (2-4\%) in nitrous oxide (60\%) and oxygen (40\%) at normocapnia as judged by continuous end-tidal $\mathrm{CO} 2$ monitoring.

A standardized intraoperative intravenous infusion was started using Ringer's lactate solution at a rate of $4 \mathrm{~mL} / \mathrm{kg} / \mathrm{hr}$. Mask acceptance score was noted according to mask acceptance score of four points where 1, 2 are satisfactory. The children were extubated at the end of surgery when awake and were thereafter immediately placed in the recovery position and allowed to wake up naturally. Behaviour at awakening was evaluated with 4-point wakeup score.

The study ended 6 hours postoperatively. The results obtained were subjected later on to statistical analysis after the completion of whole study and decoding of the study or control drug used.

\section{RESULT}

Group 1 (Midazolam) and Group 2 (Dexmedetomidine)

Group 1 received Inj. Midazolam intramuscularly $0.05 \mathrm{mg} / \mathrm{kg}$ as a premedication. Group 2 patients received Inj. Dexmedetomidine intramuscularly $1.5 \mathrm{mcg} / \mathrm{kg}$ as a premedication.

All numerical data were represented as mean \pm standard deviation (SD) and the qualitative data as frequencies. Paired ' $t$ ' test was used to analyse the differences in each treatment group before and after treatment. Unpaired ' $t$ ' test was used to compare the means between two treatment groups. To compare qualitative data, Fisher exact test and Chi-square test was performed, GraphPad InStat version 3.06 was used to calculate the above data. $\mathrm{P}$ value $<0.05$ was considered statistically significant. 
Both Groups Were Comparable According to the Following Table

Demographic Table

\begin{tabular}{|c|c|c|}
\hline & $\begin{array}{c}\text { Group 1 } \\
\text { Mean+/-SD } \\
\mathrm{N}=30 \\
\end{array}$ & $\begin{array}{c}\text { Group } 2 \\
\text { Mean+/-SD } \\
\mathrm{N}=30\end{array}$ \\
\hline Age (yrs.) & $7.3+/-2.9$ & $7.4+/-3.0$ \\
\hline \multicolumn{2}{|c|}{ P value } & 0.8979 \\
\hline Weight (kgs) & $24.3+/-7.4$ & $24.1+/-7.5$ \\
\hline \multicolumn{2}{|c|}{ P value } & 0.9178 \\
\hline
\end{tabular}

\begin{tabular}{|c|c|c|}
\hline & $\begin{array}{c}\text { Group 1 } \\
\text { (Midaz) } \\
\mathbf{N = 3 0}\end{array}$ & $\begin{array}{c}\text { Group 2 } \\
\text { (Dexmed) } \\
\mathbf{N = 3 0}\end{array}$ \\
\hline Sex (Female/Male) & $9 / 21$ & $12 / 18$ \\
\hline ASA Status (1/2) & $23 / 7$ & $21 / 9$ \\
\hline
\end{tabular}

\begin{tabular}{|c|c|c|c|}
\hline $\begin{array}{c}\text { Sedation } \\
\text { Score at 45 } \\
\text { min }\end{array}$ & $\begin{array}{c}\text { Group 1 } \\
\text { Midazolam }\end{array}$ & $\begin{array}{c}\text { Group 2 } \\
\text { Dexme- } \\
\text { detomidine }\end{array}$ & $\begin{array}{c}\text { P } \\
\text { value }\end{array}$ \\
\hline 1 & 0 & 0 & \\
\hline 2 & $5(16.6 \%)$ & 0 & \\
\hline 3 & $8(26.6 \%)$ & $3(10 \%)$ & \\
\hline 4 & $15(50 \%)$ & $7(23.3 \%)$ & \\
\hline 5 & $2(6.6 \%)$ & $14(46.6 \%)$ & \\
\hline 6 & 0 & $6(20 \%)$ & 0.007 \\
\hline $\begin{array}{c}\text { Acceptable } \\
\text { Levels 4-6 }\end{array}$ & $17(56.6 \%)$ & $27(90 \%)$ & 4 \\
\hline \multicolumn{4}{|c|}{ Ramsay Sedation Score } \\
\hline
\end{tabular}
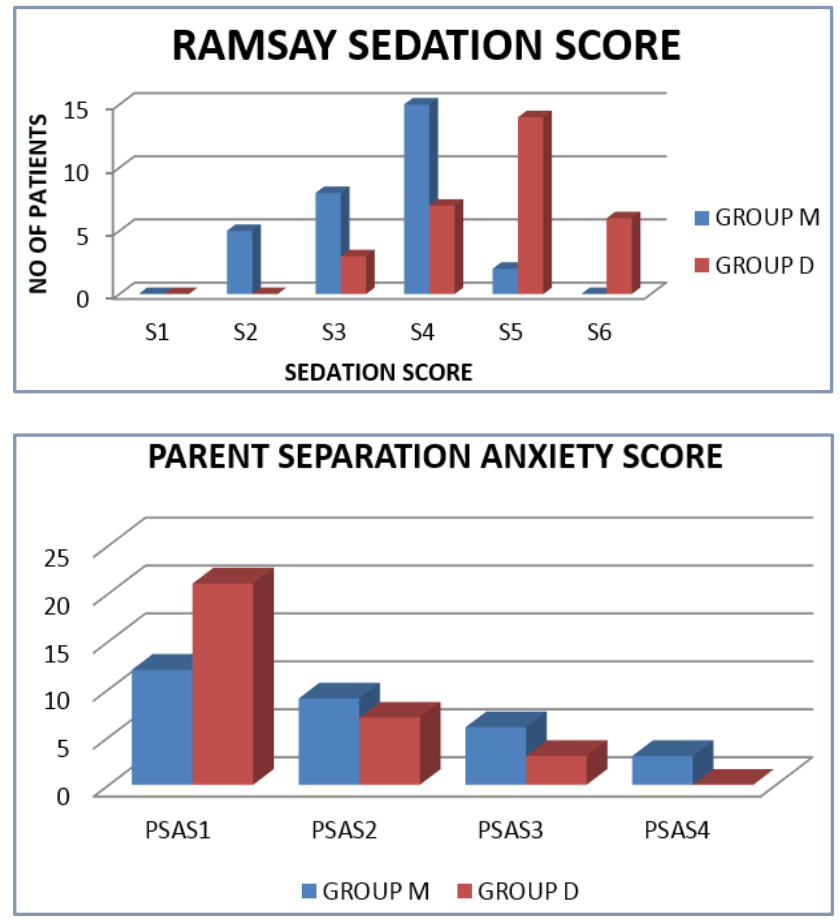

\begin{tabular}{|c|c|c|c|}
\hline $\begin{array}{c}\text { Parental } \\
\text { Separation } \\
\text { Anxiety Scale }\end{array}$ & $\begin{array}{c}\text { Group 1 } \\
\text { Midazolam }\end{array}$ & $\begin{array}{c}\text { Group 2 } \\
\text { Dexme- } \\
\text { detomidine }\end{array}$ & $\begin{array}{c}\text { P } \\
\text { value }\end{array}$ \\
\hline 1 & $12(40 \%)$ & $21(70 \%)$ & \\
\hline 2 & $9(30 \%)$ & $7(23.3 \%)$ & \\
\hline 3 & $6(20 \%)$ & $3(10 \%)$ & \\
\hline 4 & $3(10 \%)$ & 0 & 0.0419 \\
\hline $\begin{array}{c}\text { Acceptable } \\
\text { Level (1, 2) }\end{array}$ & $21(70 \%)$ & $28(93.3 \%)$ & \\
\hline \multicolumn{4}{|c|}{ Parent Separation Anxiety Score } \\
\hline
\end{tabular}

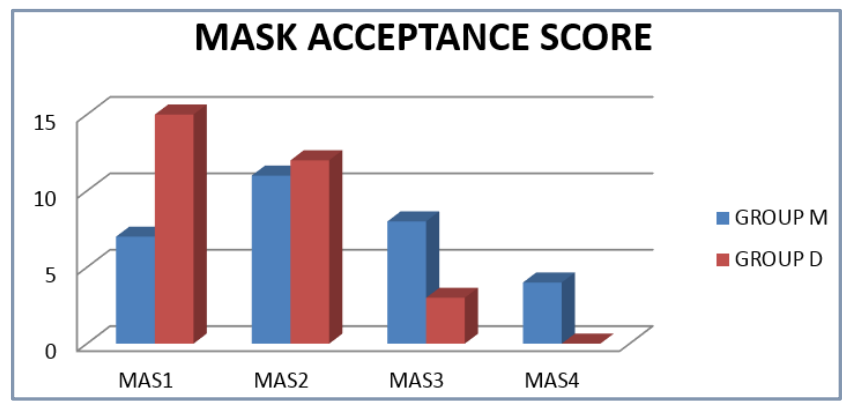

\begin{tabular}{|c|c|c|c|}
\hline $\begin{array}{c}\text { Mask } \\
\text { Acceptance } \\
\text { Score }\end{array}$ & $\begin{array}{c}\text { Group 1 } \\
\text { Midazolam }\end{array}$ & $\begin{array}{c}\text { Group 2 } \\
\text { Dexmedetomidine }\end{array}$ & P value \\
\hline 1 & $7(23.3 \%)$ & $15(50 \%)$ & \\
\hline 2 & $\begin{array}{c}11 \\
(36.6 \%)\end{array}$ & $12(40 \%)$ & \\
\hline 3 & $8(26.6 \%)$ & $3(10 \%)$ & \\
\hline 4 & $4(13.3 \%)$ & 0 & 0.0153 \\
\hline $\begin{array}{c}\text { Satisfactory } \\
\text { Levels (1,2) }\end{array}$ & $18(60 \%)$ & $27(90 \%)$ & \\
\hline \multicolumn{4}{|c|}{ Mask Acceptance Score } \\
\hline
\end{tabular}

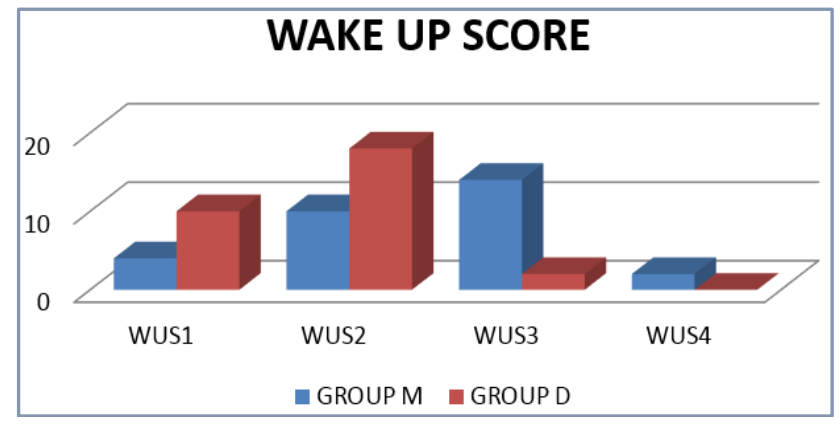

\begin{tabular}{|c|c|c|c|}
\hline $\begin{array}{c}\text { Wake Up } \\
\text { Score }\end{array}$ & $\begin{array}{c}\text { Group 1 } \\
\text { Midazolam }\end{array}$ & $\begin{array}{c}\text { Group 2 } \\
\text { Dexmedetomi- } \\
\text { dine }\end{array}$ & $\begin{array}{c}\text { P } \\
\text { value }\end{array}$ \\
\hline 1 & $4(13.3 \%)$ & $10(33.3 \%)$ & \\
\hline 2 & $10(33.3 \%)$ & $18(60 \%)$ & \\
\hline 3 & $14(46.6 \%)$ & $2(6.6 \%)$ & \\
\hline 4 & $2(6.6 \%)$ & 0 & 0.0001 \\
\hline $\begin{array}{c}\text { Acceptable } \\
\text { Level (1, 2) }\end{array}$ & $14(46.6 \%)$ & $28(93.3 \%)$ & \\
\hline \multicolumn{4}{|c|}{ Wake Up Score } \\
\hline
\end{tabular}

\section{Results of the Study were as Follows}

Our study comparing dexmedetomidine with midazolam premedication found a stable heart rate and blood pressure throughout the study in all the patients.

Sedative effects, parent separation anxiety and mask acceptance scores were comparable in both groups, (90\% vs $56 \%$ ). P value 0.0074 was found when sedation scores were compared to conclude that dexmedetomidine group had better sedative effect; 17 patients out of 30 in the midazolam group achieved adequate sedation compared to 27 in the dexmedetomidine group. Sedation achieved in the dexmedetomidine group was more than that achieved in the midazolam group. Secondary outcomes like parent separation anxiety score and mask acceptance score were also noted.

Parent separation anxiety score was better with dexmedetomidine group compared to midazolam group with p value 0.0419 (93\% vs $70 \%)$. 
21 out of 30 in the midazolam group achieved satisfactory parent separation anxiety score; 28 out of 30 in the dexmedetomidine achieved satisfactory parent separation anxiety score. A greater number of children in group dexmedetomidine achieved satisfactory parent separation anxiety score of 1 or 2 when compared with group Midazolam. Mask acceptance was better with dexmedetomidine group compared to midazolam group with p value 0.0153 (90\% vs $60 \%) ; 18$ out of 30 in the midazolam group achieved satisfactory mask acceptance score; 27 out of 30 in the dexmedetomidine achieved satisfactory mask acceptance score. A greater number of children in group Dexmedetomidine achieved satisfactory mask acceptance score of 1 or 2 when compared with group Midazolam. Similarly, wake up score were compared and dexmedetomidine had a upper hand with $\mathrm{p}$ value 0.0001 (93\% vs $46 \%$ ) compared to midazolam; 14 out of 30 in the midazolam group achieved satisfactory wake up score; 28 out of 30 in the dexmedetomidine achieved satisfactory wake up score. A greater number of children in group Dexmedetomidine achieved wake up score of 1 or 2 when compared with group Midazolam. No side effects were seen due to controlled dosage of the drug. No significant change in haemodynamic parameters were seen due to low dosages of the drug used.

\section{DISCUSSION}

Midazolam is the most commonly used anxiolytic premedication in young children. It has been successfully used through various routes, e.g. intravenous, intramuscular, oral and intranasal. ${ }^{3}$ Recently, $\alpha 2$-receptor agonists such as dexmedetomidine have also been found to be useful for premedication in children. These drugs act on central $\alpha 2$ receptors located at the presynaptic terminal where they mainly cause inhibition of release of noradrenaline. 4 This results in anxiolytic effects, sedation and analgesia without excessive drowsiness. ${ }^{5}$ Considering modern anaesthesia has advanced a long way towards eliminating the routine need for a deep preoperative sedation. ${ }^{6}$ Many studies have used a low dose intramuscular dose of midazolam $0.05 \mathrm{mg} / \mathrm{kg} .{ }^{7,8,9,10}$ Low dose of dexmedetomidine of $1.5 \mathrm{mcg} / \mathrm{kg}$ was used to prevent unwanted haemodynamic changes and other side effects. 6 Midazolam is the most commonly used agent for premedication. The major problem in everyday practice when using intranasal or oral midazolam is associated with an unpleasant burning sensation and irritation in the nasal cavity and throat. To keep the study standardized, we wanted to give both the drug with similar routes. Oral dexmedetomidine preparation being unavailable and to avoid above side effects, we chose to administer the drug intramuscularly. Sedative effect of intramuscular dexmedetomidine is observed at 45-60 mins. 11,12

All scores used for comparison in this study were standard. Sedation scores were compared using Ramsay sedation score. ${ }^{13,14}$ Anxiety during separation was evaluated by parent separation anxiety score. ${ }^{14,15}$ Mask acceptance was evaluated by mask acceptance score. $14,15,16$ While wake up behaviour was evaluated by wake up score.14,17, postoperative pain was evaluated by Face pain scale revised. ${ }^{18}$ ( $90 \%$ vs $56 \%$ ) with $\mathrm{P}$ value 0.0074 was found when sedation scores were compared to conclude that dexmedetomidine group had better sedative effect. Parent separation anxiety score was better with dexmedetomidine group compared to midazolam group with p value 0.0419 ( $93 \%$ vs $70 \%$ ).

Sedative and anxiolysis effects of intramuscular dexmedetomidine and midazolam were compared, Scheinin H.19 and Erkola 0.12 conducted a study using intramuscular dexmedetomidine as premedication for general anaesthesia comparing it with intramuscular midazolam. Dexmedetomidine and midazolam induced comparable preoperative sedation and anxiolysis. The results suggest that pre-treatment with a single intramuscular injection of dexmedetomidine is efficacious compared to midazolam. Jaakola ML. ${ }^{11}$ conducted a study to evaluate the use of intramuscular dexmedetomidine as a premedication - an alternative to midazolam-fentanyl-combination. Both premedications induced sedation and anxiolysis without any differences between the groups. Slightly different statistically, non-comparable anxiolysis was found in this study which could be due to fentanyl addition to midazolam.

C Zhou. ${ }^{20}$ Ke Peng. ${ }^{21}$ and Pasin L. compared dexmedetomidine with midazolam as a premedication in their meta-analysis; their results concluded that dexmedetomidine premedication resulted in a better sedative and anxiolytic effect during parent separation. In a study by Singlaa D. ${ }^{15}$, a double-blind, randomised study to compare dexmedetomidine versus midazolam for intranasal premedication in children posted for elective surgery. Dexmedetomidine resulted in better mask acceptance score than intranasal midazolam; similar results were seen in a study conducted by Seyedeh Z to compare oral Dexmedetomidine versus Midazolam as Anaesthetic Premedication in Children.

All the above results are closely comparable to the results found in our study.

\section{CONCLUSION}

Premedication with low-dose intramuscular dexmedetomidine resulted in better sedation, lower anxiety levels during parent separation and mask acceptance as compared with low-dose intramuscular midazolam. Comparing wake up behaviour, dexmedetomidine was a far better choice than midazolam.

Hence, it is concluded that Dexmedetomidine has a potential to be used as a superior drug compared to midazolam as an intramuscular premedication in paediatric age group.

\section{REFERENCES}

1. Kain ZN, Mayes LC, O'Connor TZ, et al. Preoperative anxiety in children predictors and outcomes. Arch Paediatr Adolesc Med 1996;150(12):1238-45.

2. Justus R, Wyles D, Wilson J, et al. Preparing children and families for surgery: mount sinai's multidisciplinary perspective. Paediatr Nurs 2006;32(1):35-43.

3. Kogan A, Katz J, Efrat R, et al. Premedication with midazolam in young children: a comparison of four routes of administration. Paediatric Anaesthesia 2002;12(8):685-9.

4. Levick JR. Control of blood vessels II: extrinsic control. In: Levick JR, editor. An introduction to cardiovascular physiology. London: Hodder Arnold. Chapter 14.1, Sympathetic vasoconstrictor nerves 2000; $3^{\text {rd }}$ ed.

5. Khan ZP, Ferguson CN, Jones RM. Alpha-2 and imidazoline receptor agonists their pharmacology and therapeutic role. Anaesthesia 1999;54(2):146-65. 
6. Xiangcai R, Yang S, Chaolei L, et al. Intramuscular dexmedetomidine as premedication. Clinical trials 2014;20:2714-9.

7. Behne M, Janshon G, Asskali F, et al. The pharmacokinetics of midazolam following intramuscular administration. Anaesthesist 1989;38(6):278-84

8. Toshiyuki Y, Yoshikazu H, Kenji U, et al. Sedative and respiratory effects of intramuscular midazolam as a premedicant: influence of gender. Journal of Anaesthesia 1994;8(4):383-6.

9. Robert SG, Lynne G, Maxwell M, et al. Preanaesthetic medication of children with midazolam using the biojector jet injector. Clinical Science Anaesthesiology 1995;83:264-9.

10. Berrin I, Mustafa A, Ozgür O, et al. The effects of 2adrenergic receptor agonist dexmedetomidine on hemodynamic response in direct laryngoscopy. The Open Otorhinolaryngology Journal 2007;1:5-11.

11. Jaakola ML, Kanto J, Scheinin H, et al. Department of anaesthesiology, turku university hospital, orion corporation farmos r\&d, finland. intramuscular dexmedetomidine premedication-an alternative to midazolam-fentanyl-combination in elective hysterectomy. Acta Anaesthesiology Scandinavia 1994;38(3):238-43.

12. Erkola $\mathrm{O}$, Korttila $\mathrm{K}$, Aho $\mathrm{M}$, et al. Comparison of intramuscular dexmedetomidine and midazolam premedication for elective abdominal hysterectomy. Anaesthesia \& Analgesia 1994;79(4):646-53.

13. Sen $S$, Thakurta RG, Gupta $S$, et al. Preoperative anxiolysis in paediatric population: a comparative study between oral midazolam and oral ketamine. Anaesth Essays Res 2013;7(2):200-5.
14. Mitra S, Kazal S, Lakesh KA. Intranasal clonidine vs. midazolam as premedication in children: a randomized controlled trial. Indian paediatric 2014;51(2):113-8.

15. Singlaa D, Chaudharya G, Durejaa J, et al. Comparison of dexmedetomidine versus midazolam for intranasal premedication in children posted for elective surgery: a double-blind, randomised study. Southern African Journal of Anaesthesia and Analgesia 2015;1(1):1-4.

16. Seyedeh Z, Mehrdad K, Ziyaeifard M, et al. Oral dexmedetomidine versus midazolam as anaesthetic premedication in children undergoing congenital heart surgery. Anaesth Pain Med 2015;5(3):e25032.

17. Pant D, Sethi N, Sood J. Comparison of sublingual midazolam and dexmedetomidine for premedication in children. Minerva Anaesthesiology 2014;80(2):167-75.

18. Hicks CL, Von Baeyer CL, Spafford PA, et al. The faces pain scale-revised: toward a common metric in paediatric pain measurement. Pain 2001;93(2):173-83.

19. Scheinin H, Jaakola ML, Sjövall S, et al. Intramuscular dexmedetomidine as premedication for general anaesthesia a comparative multicenter study. Anaesthesiology 1993;78(6):1065-75.

20. Zhou C, Zhao J. Dexmedetomidine versus midazolam as premedication in anaesthesia: a meta-analysis from randomized controlled clinical trials. J Anaesth Clin Res 2014;5(10):1-5.

21. Peng K, WU SR, Fu-Hai JI, et al. Premedication with dexmedetomidine in paediatric patients: a systematic review and meta-analysis. Clinics (Sao Paulo) 2014;69(11):777-86. 